\title{
Mycoplasma Genitalium and Mycoplasma Hominis are prevalent and correlated with HIV risk in MSM: a cross-sectional study in Shenyang, China
}

Ning Zhao ${ }^{1,5}$, Katherine T. Li ${ }^{2}$, Yang-yang Gao ${ }^{3}$, Jun-jie Xu ${ }^{3}$ and De-Sheng Huang ${ }^{1,4^{*}}$ [D

\begin{abstract}
Background: A high proportion of men who have sex with men (MSM) use geosocial networking apps (Apps) to seek partners. However, the relationship of app use with HIV risk is unknown. Further, the risks of some sexually transmitted infection (STIS), including Mycoplasma genitalium, have seldom been studied among MSM.

Methods: MSM were enrolled at a community-based HIV testing site in Shenyang, China. After completing a questionnaire survey, we collected rectal swabs and venous blood specimens. We then simultaneously tested for ten STIs (Chlamydia trachomatis [CT], Neisseria gonorrhea [NG], Ureaplasma urealyticum [Uu], Ureaplasma parvum species [Up1, Up3, Up6, Up14), Mycoplasma hominis [Mh], Mycoplasma genitalium [Mg], and Herpes Simplex Virus Type 2 (HSV-2) using multiple PCR. We also performed blood tests for HIV, Syphilis, Hepatitis C antibody (HCV-Ab), Hepatitis B Surface Antigen (HBsAg), and Hepatitis A-IgM (HAV-lgM), etc.

Results: One hundred and eighty-three MSM participated in this study, of which 51.4\% reported seeking partners through apps in the past year. The prevalence of HIV was 19.7\%, Syphilis 12.0\%, HAV 1.1\%, rectal Mg 15.3\% and Mh 7.1\%. Multivariable logistic regression showed that HIV infection was independently correlated with app-using behavior (adjusted odds ratio[aOR] $=2.6)$, Mg infection ( $\mathrm{aOR}=3.2$ ), Mh infection (aOR=4.1) and Syphilis infection (aOR=3.1) (each $P<0.05)$.

Conclusions: App use, Mg, Mh and Syphilis infection were correlated with higher HIV Risk in MSM. Geosocial networking apps should be utilized for HIV interventions targeting MSM. There is a need for more expansive STIs screening, particularly for Mg, Mh and Syphilis in MSM.
\end{abstract}

Keywords: Men who have sex with men, Sexually transmitted infection, Mycoplasma genitalium, Mycoplasma hominis, Syphilis, HIV, Geosocial networking apps

\section{Background}

There is a growing HIV epidemic among Chinese MSM. The number of new reported HIV/AIDS cases transmitted through homosexual sex increased from 26,746 in 2014 [1] to 34,358 in 2018 [2], with an average annual increase of $9.5 \%$. It is urgent to determine the factors associated with HIV infection in order to design targeted

\footnotetext{
*Correspondence: dshuang@cmu.edu.cn

'Department of Epidemiology, School of Public Health, China Medical University, Shenyang, China

${ }^{4}$ Department of Mathematics, School of Fundamental Sciences, China Medical University, Shenyang 110122, China

Full list of author information is available at the end of the article
}

intervention strategies to control the spread of HIV among MSM.

One area of investigation is the recent shift among MSM communities from offline to online methods of seeking sexual partners. Two recent prospective studies (including one from China) found that seeking sexual partners through geosocial networking apps (apps) was correlated with elevated HIV incidence in MSM [3, 4]. However, another recent meta-analysis failed to find an association between app use and HIV infection, there was an association with higher rates of other STIs [5].

(c) The Author(s). 2019 Open Access This article is distributed under the terms of the Creative Commons Attribution 4.0 International License (http://creativecommons.org/licenses/by/4.0/), which permits unrestricted use, distribution, and reproduction in any medium, provided you give appropriate credit to the original author(s) and the source, provide a link to the Creative Commons license, and indicate if changes were made. The Creative Commons Public Domain Dedication waiver (http://creativecommons.org/publicdomain/zero/1.0/) applies to the data made available in this article, unless otherwise stated. 
Thus, more studies are needed to better understand the relationship between app use and HIV risk.

Sexually transmitted infections (STIs) are another important risk factor for HIV infection in MSM [6]. STIs traditionally monitored among Chinese MSM include Chlamydia, Gonorrhoea, Hepatitis B virus (HBV), Hepatitis $\mathrm{C}$ virus (HCV) and Syphilis [7]. There is limited data on many other STIs, including Hepatitis A virus (HAV) and Mycoplasma species. HAV can spread through oral-anal intercourse and digital-rectal intercourse, and is at high risk during group sex [8]. Recently there have been multiple outbreak reports of HAV in MSM in Western countries, including Australia [9], Italy [10], England [11] and Netherlands [12]. Additionally, mycoplasma species (including both Mycoplasma genitalium [Mg] and Mycoplasma hominis [Mh]) can cause urethritis. Two studies found an association between $\mathrm{Mg}$ infection and HIV in MSM [13, 14], but one other study failed to find a significant association [15]. Testing for $\mathrm{Mg}$ is limited among MSM [16], and very few studies report the prevalence of $\mathrm{Mg}$ and $\mathrm{Mh}$ in MSM [13, 14, 17-21]. As a result, the relationships of $\mathrm{Mg}$ and $\mathrm{Mh}$ infection with HIV are not well established among MSM.

To address these gaps in knowledge regarding app use and STI infection and their relationship with HIV risk, we performed a cross-sectional study in Shenyang, China to 1) study the app-using behaviors of Chinese MSM and the relationship between app usage and HIV; and 2) determine the prevalence of traditionally monitored STIs (including Chlamydia, Gonorrhoea, Hepatitis B Surface Antigen [HBsAg], HCV-Ab and Syphilis) and neglected STIs, (including $\mathrm{HAV}, \mathrm{Mg}$ and $\mathrm{Mh}$, etc.) among MSM, and investigate the association between these STIs and HIV infection.

\section{Methods}

\section{Recruitment and data collection}

During March 2018 to October 2018, we recruited 183 MSM who sought voluntary HIV counseling and testing at the First Affiliated Hospital of China Medical University (CMU) in Shenyang, China. Eligibility criteria included (1) being at least 18 years old, (2) being biologically male; (3) self-reported anal or oral sex with another male in the past 12 months, (4) being able to provide written informed consent.

After informed consent, each participant was asked to complete an anonymous self-filled e-questionnaire [3]. We collected data on age, occupation, monthly salary, number of male sexual partners, condom use with male sexual partners, preferred sexual roles, STIs in the past 12 months, and partner-seeking methods.

Approximately $10 \mathrm{ml}$ of blood were drawn by a trained nurse. Participants then self-collected rectal swab samples for HIV and STIs testing. Unique identification numbers were used to match the e-questionnaire and laboratory test results.

\section{Collection and testing of rectal specimens}

Trained staff counseled participants on how to collect one-time rectal swabs for rectal exfoliated cells and secretions $2-3 \mathrm{~cm}$ inside the anus. We processed rectal swab sample DNA and used biotin-labeled multiple specific primers for Chlamydia [CT], Neisseria Gonorrhea [NG], Ureaplasma urealyticum [Uu], Ureaplasma parvum species [Up1, Up3, Up6, Up14], Mycoplasma hominis [Mh], Mycoplasma genitalium [Mg], and herpes simplex virus type 2 [HSV-2] fragments for PCR amplification. Amplified DNA were then hybridized with immobilized STD probes under the patented "Flowthrough Hybridization" technique using the HybriMem detection kit (KaiPU Co., Ltd. Guangzhou, China). Enzyme immunoassay method was applied for color development in order to obtain test results within $1 \mathrm{~h}$.

\section{Laboratory processing of blood samples}

We tested blood samples using the HIV-HCV (Hepatitis $\mathrm{C}$ virus)-TP (Treponema pallidum)-HBV (Hepatitis B virus) quadruplex detection reagents (Wanfu, Guangzhou) and HAV (Hepatitis A virus) detection reagent (Wanfu, Guangzhou) to detect antibodies to HIV and Treponema pallidum antibody (TP-Ab), Hepatitis C antibody (HCV-Ab), Hepatitis B Surface Antigen (HBsAg) and Hepatitis A-IgM (HAV-IgM). HIV antibody was tested by Elecsys HIV combi PT detection kit (Roche Diagnostics GmbH, Germany), and positive tests were confirmed by HIV-1/2 Western blot assay (HIV Blot 2.2 WB; MP Biomedical Asia Pacific Pte Ltd). Syphilis was tested by rapid plasma reagent (RPR Diagnosis; Shanghai, Kehua, China), and any RPR positive samples were then confirmed via Treponema pallidum particle assay (TPPA Serodia, Japan). Samples that tested positive for both RPR and TPPA were considered positive for Syphilis.

\section{Statistical analysis}

Data from the e-questionnaire and laboratory test results were analyzed using SPSS 22.0 (SPSS, Inc., Chicago, IL, USA) software. We used descriptive statistics to examine the frequency of app usage and prevalence of STIs. Chi-squared tests were used to analyze the relationships between each predictor variable and HIV infection. After adjusting for age, education and monthly economic income, we performed multivariable logistic regression analysis to obtain correlates of HIV infection reported as Odds ratios (ORs) with 95\% confidence intervals (CIs). 


\section{Results}

\section{Sociodemographics and sexual behavior}

The majority of the 183 MSM participants who completed the survey were older than 25 years $(77.0 \%)$, employed full-time $(76.5 \%)$, unmarried $(87.4 \%)$, with middle school education or above (74.3\%), and an average monthly income of $\geq 300$ US dollars (56.3\%) (Table 1).

More than half of participants mainly sought male sexual partners through apps (51.4\%), and had sexual debut between 18 and 24 years of age (51.4\%). The most common role during anal sex was versatile (39.3\%). In the past 3 -months, most had $\geq 2$ male sexual partners (79.8\%), and most had $\geq 2$ casual male sexual partners (63.9\%). Less than half had used condom with male sexual partners during anal intercourse (37.2\%) (Table 2).

\section{Prevalence of HIV/STIs infection}

The total prevalence of HIV in MSM participants was $19.7 \%$ (36/183). The prevalence of Mycoplasma hominis, Mycoplasma genitalium, Neisseria gonorrhoeae, Chlamydia trachomatis, Uu, Up1, Up3, Up6, Up14 and HSV2 were $7.1,15.3,0.5,4.4,4.4,0.0,0.0,0.0,0.0$ and $1.1 \%$, respectively. The prevalence of Syphilis was $12.0 \%$. The prevalence of HAV, HBV, and HCV were 1.1, 3.3 and $0.5 \%$ (Table 3 ).

The prevalence of HIV among subjects showed a dose-effect trend with number of STIs: for participants co-infected with $0,1,2$, and 3 STIs, the prevalence of HIV was $11.2 \%$ (12/107), 29.0\% (18/62), 38.5\% (5/13) and $100 \%(1 / 1)$, respectively (trend Chi-square $=14.610$, $P=0.001)$.

\section{Correlates of HIV infection}

Chi-square test showed that age $(P=0.003)$, monthly income $(P=0.076)$, the main routes of seeking sexual partners $(P=0.015)$, number of casual male sexual partners $(P=0.123)$, Mycoplasma hominis infection $(P=0.033)$, Mycoplasma genitalium infection $(P=0.005)$, and Syphilis infection $(P=0.008)$ were significantly associated or marginally associated with HIV infection (Tables 1 and 2).

Multivariable logistic regression analysis showed that the use of partner-seeking apps $(\mathrm{aOR}=2.6,95 \% \mathrm{CI}, 1.2-$ 5.8, $P=0.017)$, Syphilis infection $(\mathrm{aOR}=3.1,95 \% \mathrm{CI}$, 1.2-8.0, $P=0.023), \mathrm{Mg}$ infection $(\mathrm{aOR}=3.2,95 \% \mathrm{CI}$, $1.3-7.7, P=0.012)$ and $\mathrm{Mh}$ infection $(\mathrm{aOR}=2.1,95 \% \mathrm{CI}$, $1.2-13.4, P=0.020)$ were significantly associated with HIV infection (Table 4).

\section{Discussion}

We performed a cross-sectional study in Shenyang, China to determine correlates of HIV infection among MSM. We found that apps have become the predominant route of seeking male sexual partners and was independently associated with HIV infection. There was high prevalence of $\mathrm{Mg}, \mathrm{Mh}$ and Syphilis infection, and infected MSM participants also had higher HIV prevalence. The prevalence of HIV showed a significant increasing trend with increasing number of STIs in MSM participants.

The prevalence of HIV among MSM in Shenyang was found to be more than 2.5 times the national average (19.7\% vs. $7.75 \%)$ [22], and similar to prevalence estimates in the USA (14.5\%), Canada (14.9\%) and Australia (18.3\%) [23]. This highlights the urgent need for comprehensive interventions to address risk factors for HIV among MSM. Although pre-exposure prophylaxis (PrEP) has been recommended by World Health Organization since 2014 to prevent HIV for high-risk populations, PrEP is currently not available for MSM in China. There are ongoing pilot studies evaluating the acceptability, adherence and even HIV risk compensation behavior of PrEP, which may help establish national guidelines to prevent HIV.

We found that the proportion of MSM who mainly sought out male sexual partners using apps was $51.4 \%$, higher than a prior report of 43.3\% from 2009 [24].

Table 1 Demographic factors of MSM participants in Shenyang, China $(N=183)$

\begin{tabular}{|c|c|c|c|c|}
\hline Variables & & All (\%) & HIV positive (rate, \%) & $P$-value \\
\hline \multirow[t]{2}{*}{ Ages (Year) } & $18-24$ & $42(23.0)$ & $15(35.7)$ & 0.003 \\
\hline & $\geq 25$ & $141(77.0)$ & $21(14.9)$ & \\
\hline \multirow[t]{2}{*}{ Occupations } & Part-time or unemployed & $43(23.5)$ & $8(18.6)$ & 0.869 \\
\hline & Full-time employed & $140(76.5)$ & $28(20.0)$ & \\
\hline \multirow[t]{2}{*}{ Schooling education } & Middle school and below & $47(25.7)$ & $10(21.3)$ & 0.748 \\
\hline & $\begin{array}{l}\text { Completed middle school } \\
\text { and above }\end{array}$ & $136(74.3)$ & $26(19.1)$ & \\
\hline \multirow[t]{2}{*}{ Marriage status } & Married & $23(12.6)$ & $4(17.4)$ & 0.769 \\
\hline & Unmarried & $160(87.4)$ & $32(20.0)$ & \\
\hline \multirow[t]{2}{*}{ Monthly income (USD, dollar) } & $<300$ & $80(43.7)$ & $11(13.8)$ & 0.076 \\
\hline & $\geq 300$ & $103(56.3)$ & $25(24.3)$ & \\
\hline
\end{tabular}


Table 2 Sexual behavior of MSM participants in Shenyang, China $(N=183)$

\begin{tabular}{|c|c|c|c|c|}
\hline Variables & & All (\%) & HIV positive (rate, \%) & $P$-value \\
\hline \multirow[t]{2}{*}{ Main partner-seeking methods } & Non-APPs & 89 (48.6) & $11(12.4)$ & \multirow[t]{2}{*}{0.015} \\
\hline & APPs & $94(51.4)$ & $25(26.6)$ & \\
\hline \multirow[t]{3}{*}{ Sexual debut age (years) } & $<18$ & $52(28.4)$ & $11(21.2)$ & \multirow[t]{3}{*}{0.950} \\
\hline & $18-24$ & $94(51.4)$ & $18(19.1)$ & \\
\hline & $\geq 25$ & $37(20.2)$ & $7(18.9)$ & \\
\hline \multirow[t]{3}{*}{ Sexual roles with partners } & Bottom & $49(26.8)$ & $12(24.5)$ & \multirow[t]{3}{*}{0.402} \\
\hline & Top & $62(33.9)$ & $9(14.5)$ & \\
\hline & Versatile & $72(39.3)$ & $15(20.8)$ & \\
\hline \multirow[t]{2}{*}{ Male circumcision } & Yes & $11(6.0)$ & $1(9.1)$ & \multirow[t]{2}{*}{0.362} \\
\hline & No & $172(94)$ & $35(20.3)$ & \\
\hline \multicolumn{5}{|l|}{ Sexual behaviors in recent 3-months } \\
\hline \multirow[t]{2}{*}{ No. of total male sexual partners } & $0-1$ & $37(20.2)$ & $5(13.5)$ & \multirow[t]{2}{*}{0.291} \\
\hline & $\geq 2$ & $146(79.8)$ & $31(21.2)$ & \\
\hline \multirow[t]{2}{*}{ No. of casual male sexual partners } & $0-1$ & $65(36.1)$ & $9(13.8)$ & \multirow[t]{2}{*}{0.141} \\
\hline & $\geq 2$ & $118(63.9)$ & $27(22.9)$ & \\
\hline \multirow{3}{*}{$\begin{array}{l}\text { Using condom with partners } \\
\text { during anal intercourse }\end{array}$} & Always & $68(37.2)$ & $12(17.6)$ & \multirow[t]{3}{*}{0.684} \\
\hline & Occasionally & $83(45.4)$ & 16 (19.3) & \\
\hline & Never used & $32(17.5)$ & $8(25.0)$ & \\
\hline
\end{tabular}

Further, MSM who mainly sought out male sexual partners using apps had 2.6 times the risk of HIV infection than MSM who mainly sought partners through other methods. This is consistent with results from two recent longitudinal cohort studies in MSM [3, 4], but differs from a recent Meta-analysis [5]. Our study results indicate that more effort should be dedicated to surveillance of MSM who seek sexual partners through apps and adaption of HIV prevention measures onto social networking mobile app platforms. One recent innovative intervention was implemented through an app popular among Chinese MSM to promote HIV testing and condom use [25, 26].

We simultaneously measured the prevalence of ten important STIs, including $\mathrm{Mh}, \mathrm{Mg}, \mathrm{NG}$, and CT by using a novel multiple PCR (M-PCR) testing method [27]. This method may have important applications in STIs screening. In general, we found that the prevalence of HIV in MSM participants showed a significant doseresponse trend with increased number of STIs. This further highlights the need for STI screening as a part of comprehensive HIV prevention.

In particular, we found that rectal infection with $\mathrm{Mg}$ was $15.3 \%$, almost three times higher than rates reported from Shenzhen (5.4\%) in 2014 [17], Italy (4.8\%) [20] and Australia (8.9\%) [18]. The prevalence of rectal $\mathrm{Mg}$ in HIV-positive MSM in this study was 4.8 times that reported in the US (30.6\% vs. 6.4\%) [21]. Additionally, we found that $\mathrm{Mg}$ infection was associated with a 3.2 times higher risk of HIV. Coinfection with Mg may cause mucosal disruption and inflammation that increases susceptibility to HIV $[28,29]$. This result suggests that it is important to test and treat for Mg in Chinese MSM.

Similarly, we found a high prevalence of rectal Mh (7.1\%), though lower than reports from MSM in Northern Ireland (24.3\%) [19]. To our best knowledge, the relationship between Mh and HIV infection in MSM has not been previously reported. We found that $\mathrm{Mh}$ infection was associated with a 4.1 times risk of HIV infection, which was even greater than the association between HIV and Syphilis infection $(\mathrm{aOR}=2.99)$ [30]. Our study suggests that Chinese MSM should also be screened for Mh. More research is required to investigate this association, and screening and treatment of Mh-positive MSM should be explored as a potential method of HIV prevention strategy.

We also noted the prevalence of HAV for the first time in an MSM population in mainland China. We found that it was higher than the HAV prevalence in the general population in US ( $1.1 \%$ vs. 1.3 per 100,000 population), but lower than that of MSM in the US (3.9\%) [31]. Although the prevalence of HAV in our study appears to be lower than the prevalence reports from MSM in Korea (37.3\%) and Bangkok (32.4\%), but these two studies both measured HAV-IgG and not HAV-IgM, and may not be comparable with our result. Our result highlights the importance of screening for HAV and HAV vaccination among China MSM. China has had a free HBV vaccination program since 1992, but only implemented a free HAV vaccination program in 2008 [32], so 
Table 3 Correlates of HIV infection and other STIs in MSM attendants in Shenyang, China $(N=183)$

\begin{tabular}{|c|c|c|c|c|}
\hline \multicolumn{2}{|l|}{ Variables } & All (\%) & $\begin{array}{l}\text { HIV Positive } \\
\text { (rate, \%) }\end{array}$ & $P$-value \\
\hline \multicolumn{5}{|c|}{ DNA test of 10-STIs } \\
\hline \multirow[t]{2}{*}{ Mh. } & No & $170(92.9)$ & $30(17.6)$ & 0.013 \\
\hline & Yes & $13(7.1)$ & $6(46.2)$ & \\
\hline \multirow[t]{2}{*}{ Mg. } & No & $155(84.7)$ & $25(16.1)$ & 0.005 \\
\hline & Yes & $28(15.3)$ & $11(39.3)$ & \\
\hline \multirow[t]{2}{*}{$N G$} & No & $182(99.5)$ & $36(19.8)$ & 0.620 \\
\hline & Yes & $1(0.5)$ & $0(0.0)$ & \\
\hline \multirow[t]{2}{*}{$C T$} & No & 175 (95.6) & $35(20.0)$ & 0.602 \\
\hline & Yes & $8(4.4)$ & $1(12.8)$ & \\
\hline \multicolumn{5}{|c|}{ Ureaplasma Urealyticum } \\
\hline \multirow[t]{2}{*}{ Unu } & No & $175(95.6)$ & $34(19.4)$ & 0.698 \\
\hline & Yes & $8(4.4)$ & $2(25.0)$ & \\
\hline \multirow[t]{2}{*}{ Uup1 } & No & $183(100.0)$ & $36(19.7)$ & NA \\
\hline & Yes & $0(0.0)$ & & \\
\hline \multirow[t]{2}{*}{ Uup3 } & No & $183(100.0)$ & $36(19.7)$ & NA \\
\hline & Yes & $0(0.0)$ & NA & \\
\hline \multirow[t]{2}{*}{ Uup6 } & No & $183(100.0)$ & $36(19.7)$ & NA \\
\hline & Yes & $0(0.0)$ & NA & \\
\hline \multirow[t]{2}{*}{ Uup14 } & No & $183(100.0)$ & $36(19.7)$ & NA \\
\hline & Yes & $0(0.0)$ & NA & \\
\hline \multirow[t]{2}{*}{ HSV-2 } & No & $181(98.9)$ & $36(19.9)$ & 0.482 \\
\hline & Yes & $2(1.1)$ & $0(0.0)$ & \\
\hline \multirow[t]{2}{*}{ Plasma syphilis ${ }^{a}$} & No & $161(88.0)$ & $27(16.8)$ & 0.008 \\
\hline & Yes & $22(12.0)$ & $9(40.9)$ & \\
\hline \multicolumn{5}{|c|}{ Rapid test of Hepatitis } \\
\hline \multirow[t]{2}{*}{ HAV-IgM } & No & $181(98.9)$ & 36 (19.8) & 0.210 \\
\hline & Yes & $2(1.1)$ & $0(0.0)$ & \\
\hline \multirow[t]{2}{*}{$\mathrm{HBsAg}$} & No & $177(96.7)$ & $34(19.2)$ & 0.392 \\
\hline & Yes & $6(3.3)$ & $2(33.3)$ & \\
\hline \multirow[t]{2}{*}{$\mathrm{HCV}-\mathrm{Ab}$} & No & $182(99.5)$ & $36(19.8)$ & 0.620 \\
\hline & Yes & $1(0.5)$ & $0(0.0)$ & \\
\hline
\end{tabular}

a both RPR and TPPA positive testing results were regarded as currently infected with syphilis. Uu ureaplasma urealyticum, Up Ureaplasma parvum

Table 4 Multivariable analysis of correlates of HIV infection in MSM attendants in Shenyang, China $(N=183)$

\begin{tabular}{lll}
\hline Variables & $\mathrm{aOR}(95 \% \mathrm{Cl})^{\mathrm{a}}$ & $P$-value \\
\hline Use of partner-seeking apps & $2.6(1.2-5.8)$ & 0.017 \\
Mycoplasma genitalium infection & $3.2(1.3-7.7)$ & 0.012 \\
Mycoplasma hominis infection & $4.1(1.2-13.4)$ & 0.020 \\
Syphilis infection & $3.1(1.2-8.0)$ & 0.023 \\
\hline
\end{tabular}

a, adjusted for age, education and monthly economic income
Chinese MSM who are over 11 years or 27 years old are unlikely to have received the HAV vaccine and HBV vaccine, respectively. And there were scarcely plans or recommendations in China to provide HAV or HBV vaccination for MSM population. Hence our study indicated that the screening and vaccination against HAV and HBV among sexually active Chinese MSM should be considered, especially among the high risk individuals for HAV and HBV infection.

This study has several limitations. First, we only collected rectal swab specimens and did not collect urethral or oral swab specimens, so the overall prevalence of STIs is an underestimate. Secondly, we only used PCR testing for $\mathrm{Mg}, \mathrm{Mh}, \mathrm{NG}, \mathrm{CT}$, etc. and prevalence rates of STIs in this study may not be comparable with studies using culture or other diagnostic methods. Third, this is a cross-sectional design, which cannot determine the causal relationships between HIV and other STIs. Fourth, the study sample size is relatively small, which limits the statistical power of this study. Finally, MSM participants were recruited by convenience sampling from MSM seeking out HIV counseling and testing, and it is unclear whether this result is generalizable to the HIV prevalence of the general MSM population in Shenyang.

\section{Conclusions}

There is increasing partner-seeking app usage among MSM, and app usage is correlated with risk of HIV infection. App platforms should be utilized to conduct HIV prevention interventions. $\mathrm{Mg}$ and $\mathrm{Mh}$ were both highly prevalent in our study, and both were independent risk factors for HIV infection. More effort should be dedicated to the screening, prevention and treatment of Mycoplasma genitalium and Mycoplasma homini infection, in order to curb the spread of HIV among MSM.

\section{Abbreviations \\ Cl: Confidence interval; CT: Chlamydia trachomatis; Mg: Mycoplasma genitalium; Mh: Mycoplasma hominis; M-PCR: Multiple PCR; MSM: Men who have sex with men; NG: Neisseria gonorrhoea; ORs: Odds ratios; RPR: Rapid plasma reagent; STI: Sexually transmitted infection; TPPA: Treponema pallidum particle assay; Up: Ureaplasma parvum; Uu: Ureaplasma urealyticum}

\section{Acknowledgements}

The authors thank all the MSM participants who joined this study for their time spent for this project, and all of the health care and laboratory staff at all levels who participated in HIV/AIDS diagnoses, and data collection for this study.

\section{Authors' contributions}

Authors are cited in the same order that they are cited in the title page. NZ analyzed the data and drafted the manuscript. KTL curated the data reviewed and edited the manuscript. YYG performed the laboratory testing, collected and validated the data. JJX collected and curated the data, drafted the manuscript, secured funding. DSH provided overall leadership to the study, participated in the analysis and secured funding. All authors have read and approved the final manuscript. 


\section{Funding}

This work is partially supported by the National Natural Science Foundation of China (Grant No. 81872674 and 71573275). The funders had no role in study design, data collection and analysis, decision to publish, or preparation of the manuscript.

\section{Availability of data and materials}

The datasets used and/or analyzed during the current study are available from the corresponding author on reasonable request.

\section{Ethics approval and consent to participate}

All participants gave written informed consent prior to participating in the study. Each participant was clearly informed that he could decline or withdraw from the survey at any time. The e-questionnaire and written consent document were separately kept under a specific account and in locked drawers at the research sites, which were inaccessible to anyone but research staff. The study protocol and consent were approved by the Ethics Review Committee of the First Affiliated Hospital of China Medical University (Ethical Review [2018] No. 38).

\section{Consent for publication}

Not applicable.

\section{Competing interests}

The authors declare that they have no competing interest.

\section{Author details}

'Department of Epidemiology, School of Public Health, China Medical University, Shenyang, China. ${ }^{2}$ Weill Cornell Medical College, New York, NY, USA. ${ }^{3}$ Key Laboratory of AIDS Immunology of National Health Commission, Department of Laboratory Medicine, The First Affiliated Hospital, China Medical University, Shenyang 110001, Liaoning, China. ${ }^{4}$ Department of Mathematics, School of Fundamental Sciences, China Medical University, Shenyang 110122, China. ${ }^{5}$ Department of Ophthalmology, The First Affiliated Hospital of China Medical University, Shenyang, China.

\section{Received: 19 March 2019 Accepted: 28 May 2019}

Published online: 04 June 2019

\section{References}

1. NCAIDS, NCSTD, China CDC. Update on the AIDS/STD epidemic in China and main response in control and prevention in December, 2014. Chin J AIDS STD. 2015;21(2):87.

2. NCAIDS, NCSTD, ChinaCDC. Update on the AIDS/STD epidemic in China in December 2017. Chin J AIDS STD. 2018;24(2):111.

3. Xu J, Yu H, Tang W, Leuba Sl, Zhang J, Mao X, Wang H, Geng W, Jiang Y, Shang $H$. The effect of using geosocial networking apps on the HIV incidence rate among men who have sex with men: eighteen-month prospective cohort study in Shenyang, China. J Med Internet Res. 2018; 20(12):e11303.

4. Piyaraj P, Griensven FV, Holtz TH, Mock PA, Varangrat A, Wimonsate W, Thienkrua W, Tongtoyai J, Mcnamara A, Chonwattana W. The finding of casual sex partners on the internet, methamphetamine use for sexual pleasure, and incidence of HIV infection among men who have sex with men in Bangkok, Thailand: an observational cohort study. Lancet HIV. 2018:e379-89.

5. Wang H, Zhang L, Zhou Y, Wang K, Zhang X, Wu J, Wang G. The use of geosocial networking smartphone applications and the risk of sexually transmitted infections among men who have sex with men: a systematic review and meta-analysis. BMC Public Health. 2018;18(1):1178.

6. Beyrer C, Baral SD, Griensven FV, Goodreau SM, Chariyalertsak S, Wirtz AL, Brookmeyer R. Global epidemiology of HIV infection in men who have sex with men. Lancet. 2012;380(9839):367-77.

7. Chow EPF, Tucker JD, Wong FY, Nehl EJ, Yanjie W, Xun Z, Lei Z. Disparities and risks of sexually transmissible infections among men who have sex with men in China: a meta-analysis and data synthesis. PLoS One. 2014;9(2):e89959.

8. Henning KJ, Bell E, Braun J, Barker ND. A community-wide outbreak of hepatitis a: risk factors for infection among homosexual and bisexual men. Am J Med. 1995;99(2):132-6.
9. Weerakoon AP, Chen MY, Read TR, Bradshaw C, Fairley CK. Immunity to hepatitis a when outbreaks of infection in men who have sex with men (MSM) are rare. Vaccine. 2012;30(23):3430-4.

10. Bordi L, Rozera G, Scognamiglio P, Minosse C, Loffredo M, Antinori A, Narciso P, Ippolito G, Girardi E, Capobianchi MR. Monophyletic outbreak of hepatitis a involving HIV-infected men who have sex with men, Rome, Italy 2008-2009. J Clin Virol. 2012;54(1):26-9.

11. Beebeejaun K, Degala S, Balogun K, Simms I, Woodhall SC, Heinsbroek E, Crook PD, Kar-Purkayastha I, Treacy J, Wedgwood K, et al. Outbreak of hepatitis a associated with men who have sex with men (MSM), England, July 2016 to January 2017. Euro Surveill. 2017;22(5):30454.

12. Freidl GS, Sonder GJ, Bovee LP, Friesema $\|_{H}$, van Rijckevorsel GG, Ruijs WL, van Schie F, Siedenburg EC, Yang JY, Vennema H. Hepatitis a outbreak among men who have sex with men (MSM) predominantly linked with the EuroPride, the Netherlands, July 2016 to February 2017. Euro Surveill. 2017;22(8):30468.

13. Soni S, Alexander S, Verlander N, Saunders P, Richardson D, Fisher M, Ison C. The prevalence of urethral and rectal mycoplasma genitalium and its associations in men who have sex with men attending a genitourinary medicine clinic. Sex Transm Infect. 2010;86(1):21-4.

14. Bissessor M, Tabrizi SN, Bradshaw CS, Fairley CK, Hocking JS, Garland SM, Twin J, Poljak M, Peel J, Chen MY. The contribution of mycoplasma genitalium to the aetiology of sexually acquired infectious proctitis in men who have sex with men. Clin Microbiol Infect. 2016;22(3):260-5.

15. Libois A, Hallin M, Crucitti T, Delforge M, De Wit S. Prevalence of mycoplasma genitalium in men with urethritis in a large public hospital in Brussels, Belgium: an observational, cross-sectional study. PLoS One. 2018; 13(4):e0196217.

16. Tucker JD, Ong JJ. Mycoplasma genitalium: an important sexually transmitted infection comes into focus. Sex Transm Infect. 2018;94(4):240-1.

17. Zheng BJ, Yin YP, Han Y, Shi MQ, Jiang N, Xiang Z, Yu RX, Zhang GY, Chen XS. The prevalence of urethral and rectal mycoplasma genitalium among men who have sex with men in China, a cross-sectional study. BMC Public Health. 2014;14:195.

18. Couldwell DL, Jalocon D, Power M, Jeoffreys NJ, Chen SC, Lewis DA Mycoplasma genitalium: high prevalence of resistance to macrolides and frequent anorectal infection in men who have sex with men in western Sydney. Sex Transm Infect. 2018;94(6):406-10.

19. Cox C, Watt AP, Mckenna JP, Coyle PV. Gardnerella vaginalis and Mollicute detection in rectal swabs from men who have sex with men. Int J STD AIDS. 2017;28(7):708-14.

20. Foschi C, Gaspari V, Sgubbi P, Salvo M, D'Antuono A, Marangoni A. Sexually transmitted rectal infections in a cohort of 'men having sex with men'. J Med Microbiol. 2018;67(8):1050-7.

21. Dionne-Odom J, Geisler WM, Aaron KJ, Waites KB, Westfall AO, Van Der Pol $\mathrm{B}$, Xiao L. High prevalence of multidrug-resistant mycoplasma genitalium in human immunodeficiency virus-infected men who have sex with men in Alabama. Clin Infect Dis. 2018:66(5):796-8.

22. Qin Q, Tang W, Ge L, Li D, Mahapatra T, Wang L, Guo W, Cui Y, Sun J. Changing trend of HIV, syphilis and hepatitis C among men who have sex with men in China. Sci Rep. 2016;6:31081.

23. UNAIDS. Key populations atlas, Men who have sex with men. URL: http:// www.aidsinfoonline.org/kpatlas/\#/home. Accessed on May $20^{\text {th }} 2019$.

24. Pan S, Xu JJ, Han XX, Zhang J, Hu QH, Chu ZX, Hai YQ, Mao X, Yu YQ, Geng WQ. Internet-based sex-seeking behavior promotes HIV infection risk: a 6year serial cross-sectional survey to MSM in Shenyang, China. Biomed Res Int. 2016;2016(2):2860346.

25. Liu C, Mao J, Wong T, Tang W, Lai ST, Tang S, Zhang Y, Zhang W, Qin Y, Chen Z. Comparing the effectiveness of a crowdsourced video and a social marketing video in promoting condom use among Chinese men who have sex with men: a study protocol. BMJ Open. 2016;6(10):e010755.

26. Tang W, Wei C, Cao B, Wu D, Li KT, Lu H, Ma W, Kang D, Li H, Liao M, et al. Crowdsourcing to expand HIV testing among men who have sex with men in China: a closed cohort stepped wedge cluster randomized controlled trial. PLoS Med. 2018;15(8):e1002645.

27. Souza RP, de Abreu AL, Ferreira EC, Rocha-Brischiliari SC, de BCMD, Pelloso SM, Bonini MG, Gimenes F, Consolaro ME. Simultaneous detection of seven sexually transmitted agents in human immunodeficiency virus-infected Brazilian women by multiplex polymerase chain reaction. Am J Trop Med Hyg. 2013;89(6):1199-202.

28. Tully JG, Taylor-Robinson D, Rose DL, Furr PM, Graham CE, Barile MF. Urogenital challenge of primate species with mycoplasma genitalium 
and characteristics of infection induced in chimpanzees. J Infect Dis. 1986;153(6):1046-54.

29. Zhang S, Wear DJ, Lo SC. Mycoplasmal infections alter gene expression in cultured human prostatic and cervical epithelial cells. FEMS Immunol Med Microbiol. 2000;27(1):43-50.

30. Zhang W, Xu JJ, Zou H, Zhang J, Wang N, Shang H. HIV incidence and associated risk factors in men who have sex with men in mainland China: an updated systematic review and meta-analysis. Sex Health. 2016;13(4):373-82

31. Klevens RM, Miller JT, Iqbal K, Thomas A, Rizzo EM, Hanson H, Sweet K, Phan Q, Cronquist A, Khudyakov Y, Xia GL, Spradling P. The evolving epidemiology of hepatitis a in the United States: incidence and molecular epidemiology from population-based surveillance, 2005-2007. Arch Intern Med. 2010;170(20):1811-8.

32. Fifteen infectious diseases such as hepatitis $A$, encephalorrhagia and so on are included in the national immunization plan. URL. http://www.gov.cn/ gzdt/2008-02/19/content_893572.htm. Accessed on May 20 2019.

\section{Publisher's note}

Springer Nature remains neutral with regard to jurisdictional claims in published maps and institutional affiliations.

Ready to submit your research? Choose BMC and benefit from:

- fast, convenient online submission

- thorough peer review by experienced researchers in your field

- rapid publication on acceptance

- support for research data, including large and complex data types

- gold Open Access which fosters wider collaboration and increased citations

- maximum visibility for your research: over $100 \mathrm{M}$ website views per year

At $\mathrm{BMC}$, research is always in progress.

Learn more biomedcentral.com/submissions 